\title{
Pseudomonas fluorescens LBUM223 Increases Potato Yield and Reduces Common Scab Symptoms in the Field
}

\author{
Tanya Arseneault, Claudia Goyer, and Martin Filion
}

First and third authors: Université de Moncton, Department of Biology, Moncton, NB, Canada; and second author: Potato Research Center, Agriculture and Agri-Food Canada, Fredericton, NB, Canada. Accepted for publication 3 May 2015.

\begin{abstract}
Arseneault, T., Goyer, C., and Filion, M. 2015. Pseudomonas fluorescens LBUM223 increases potato yield and reduces common scab symptoms in the field. Phytopathology 105:1311-1317.

Common scab of potato, caused by pathogenic Streptomyces spp., is an important disease not efficiently controlled by current methods. We previously demonstrated that Pseudomonas fluorescens LBUM223 reduces common scab development under controlled conditions through phenazine-1-carboxylic (PCA) production, leading to reduced thaxtomin A production by the pathogen, a key pathogenicity and virulence factor. Here, we aimed at determining if LBUM223 is able to increase potato yield and control common scab under field conditions, while character-

in pathogen soil populations, activation of induced systemic resistance in potato, and/or changes in txtA gene expression, involved in thaxtomin A biosynthesis in pathogenic Streptomyces spp. were involved in common scab control by LBUM223. Common scab symptoms were significantly reduced and total tuber weight increased by $46 \%$ using biweekly applications of LBUM223. LBUM223 did not reduce pathogen soil populations, nor was potato systemic defense-related gene expression significantly altered between treatments. However, a significant downregulation of $t x t A$ expression occurred in the geocaulosphere. This is the first demonstration that a Pseudomonas strain can directly alter the transcriptional activity of a key pathogenesis gene in a plant pathogen under field conditions, contributing to disease control.
\end{abstract} izing the biocontrol mechanisms involved. We investigated if a reduction
Common scab is a bacterial infection of potato (Solanum tuberosum L.) caused by Streptomyces scabies and other Streptomyces species, which induce necrotic lesions that affect potato marketability (Lambert and Loria 1989). It has been shown that the main genes responsible for disease development, such as $t x t A$ (Loria et al. 2008), are conserved in a mobile pathogenicity island. The txtA gene has been shown to be conserved among common scabcausing Streptomyces species (Healy et al. 2002) and encodes the TxtA protein, which is involved in the biosynthesis of the $\mathrm{N}$-methylated dipeptide backbone of thaxtomin A. The production of thaxtomin A is essential to the development of necrotic lesions found on tuber surface (Goyer et al. 1998; Lawrence et al. 1990), and has been positively associated with the severity of common scab symptoms (Kinkel et al. 1998), making it a key pathogenicity factor as well as virulence factor.

Controlling common scab under commercial agricultural conditions remains difficult. Current practices mainly rely on crop rotations as well as irrigation and $\mathrm{pH}$ adjustment (Dees and Wanner 2012). However, these approaches rarely succeed at completely preventing common scab development when the pathogen is present in sufficient quantities, especially at the early developing tuber stage, which usually leads to more severe symptoms on harvested tubers (Khatri et al. 2011). The development of other approaches for controlling this disease is therefore needed.

We previously showed that biological control of common scab was achieved using the phenazine-1-carboxylic acid (PCA)producing fluorescent Pseudomonas fluorescens LBUM223 under controlled soil conditions (Arseneault et al. 2013). The reduction in disease was attributed to a decrease in the virulence of $S$. scabies, observed by a down-regulation in $t x t A$ gene expression, which led

Corresponding author: M. Filion; E-mail address: martin.filion@umoncton.ca to a significant reduction in symptoms. Interestingly, S. scabies populations in the soil surrounding tubers (geocaulosphere) were not reduced in the presence of LBUM223, suggesting that the amount of PCA produced is not toxic to the pathogen. However, the production of PCA by LBUM223 was required for biological control since an isogenic PCA-deficient mutant of LBUM223 was incapable of reducing scab symptoms. LBUM223 was also found to act as a plant growth promoting rhizobacterium by increasing total plant weight in pot experiments (Arseneault et al. 2013). Validation of these biocontrol and growth-promoting activities under natural field conditions is however needed to further develop LBUM223 as a potential biocontrol agent (BCA) for common scab.

Fluorescent Pseudomonas spp., such as LBUM223, have proven to be useful BCAs, due to their high root colonization and rhizosphere competence (Weller 2007), their capacity in producing various antimicrobial compounds, including phenazines (Chin-A-Woeng et al. 2003), or their ability in inducing plant defense responses (Bakker et al. 2007), leading to a better protection against diseases via induced systemic resistance (ISR) (Pieterse et al. 2014). Such a defense response is modulated by a large number of hormonal messengers, the backbone of the signaling network consisting of salicylic acid (SA), generally associated with a systemic acquired resistance response, and jasmonic acid (JA)/ethylene (ET), generally associated with ISR (Pieterse et al. 2012). We previously showed that LBUM223 was able to induce the overexpression of two systemic defense-related genes in potato leaves, $P R-5$ and $L O X$. However, the overexpression of these genes was not associated with a reduction in common scab symptoms under controlled conditions (Arseneault et al. 2014). This does not rule out the possibility that LBUM223 is able to trigger an ISR response in potato under more complex field conditions.

The aims of this study were (i) to determine if P. fluorescens LBUM223 is able to control common scab of potato under field conditions using a single or biweekly application(s) with LBUM223, (ii) to investigate if a decrease in pathogen populations, changes in txtA expression in pathogenic Streptomyces spp., and/or activation of 
a systemic resistance response in potato are involved, and (iii) to determine if LBUM223 can increase potato yield through growthpromoting activity.

\section{MATERIALS AND METHODS}

P. fluorescens LBUM223 inoculum. P. fluorescens LBUM223 was originally isolated from the rhizosphere of a strawberry plant in a field in Bouctouche, Canada (Paulin et al. 2009). The genome of LBUM223 has recently been sequenced (GenBank accession CP011117) and was shown to belong to the subclade 3 among the $P$. fluorescens group described by Loper and colleagues (2012) (Roquigny et al. 2015). Liquid inoculum was prepared by growing LBUM 223 at $25^{\circ} \mathrm{C}$ for 3 days in tryptic soy broth (BD, Franklin Lakes, NJ) with shaking at $200 \mathrm{rpm}$. Populations were estimated using spectrophotometer readings $(\lambda=600 \mathrm{~nm})$ and a standard curve. For inoculations (single or biweekly), each plant (or seed tuber piece) received $20 \mathrm{ml}$ of the aforementioned LBUM223 culture at a concentration of $2.5 \times 10^{9} \mathrm{CFU} / \mathrm{ml}$ (total of $5 \times 10^{10}$ $\mathrm{CFU} /$ plant). Control seeds received the same volume of water at planting only.

Field trials. Two trials were conducted at the Potato Research Centre of Agriculture and Agri-Food Canada (Fredericton, NB, Canada) in an agricultural field (latitude $45^{\circ} 55^{\prime} 13.000^{\prime \prime} \mathrm{N}$, longitude $66^{\circ} 36^{\prime} 32.010^{\prime \prime} \mathrm{W}$, WMO ID: 71668) naturally containing common scab-causing pathogenic Streptomyces spp. The soil is a sandy loam ( $58.7 \%$ sand, $24.9 \%$ silt, and $16.4 \%$ clay) with a $\mathrm{pH}$ of 5.8. The experiments were conducted from June to September, in 2012 and 2013. The field was divided into six (2013) or eight (2012) blocks, surrounded by guard rows, containing randomized treatment plots of 10 potato plants ('Kennebec'). Treatments included the following: (i) control (no application), (ii) single LBUM223 application, and (iii) biweekly applications with LBUM223 (2013 trial only). LBUM223 was applied at planting (single), and then also at 3,5, 7, and 9 weeks after planting for the biweekly applications treatment. Control seed tubers received the same volume of water at planting only. Applications were made by directly pipetting the inoculum (or water) onto the seed tubers prior to covering with soil. For biweekly applications, the inoculum was applied in the same manner to the base of each plant. The field was subjected to conventional potato-growing practices. Destructive sampling of one randomly selected plant per plot occurred in the field at weeks $3,5,7,9$, and 11 , for a total of six or eight plants per treatment, per time. Plants were gently shoveled from the soil with their tubers intact and attached. The tubers were shaken to remove loosely adhering soil, and the soil remaining on the tubers was wiped off, collected, and labeled as geocaulosphere. No tubers were present at 3 and 5 weeks, and consequently no potato geocaulosphere was sampled at these times. Twelve leaves were randomly selected and collected from each plant. Soil and leaves samples were immediately frozen in liquid nitrogen on site and subsequently stored at $-80^{\circ} \mathrm{C}$. Disease severity was assessed by estimating the percentage of common scab lesion coverage on each harvested tuber, and was evaluated at each sampling date when potatoes were collected. Values were averaged for all tubers originating from the same plant. Disease incidence was calculated by determining the proportion of tubers with $>5 \%$ scab coverage (above which tubers' marketability is highly reduced in Canadian governmental grading regulations) divided by the total number of harvested tubers. Total tuber weight for each plant was also determined. At the end of the growing season (17 weeks after planting), the remaining tubers were collected from each plot and weighed, and common scab symptoms were assessed as described above.

Extraction of DNA and RNA from soil. Geocaulosphere soil samples were lyophilized prior to nucleic acid extractions. DNA was extracted using the UltraClean Soil DNA Isolation Kit (Mobio, Carlsbad, CA) following manufacturer instructions, except for the vortex mixing step, which was substituted with the use of a FastPrep (QBiogene, MP Biomedicals, Santa Ana, $\mathrm{CA}$ ) at a speed of $5.5 \mathrm{~ms}^{-1}$ during $45 \mathrm{~s}$. Extracted DNA (between 30 to $50 \mathrm{ng} / \mu \mathrm{l}$ ) was diluted $1: 10$ prior to quantitative polymerase chain reaction (qPCR) analyses. The same soil samples were also submitted to RNA extraction using the protocol described by Bürgmann et al. (2003), with some modifications and two subsequent DNAse treatments, as previously described (Arseneault et al. 2013). RNA yield was consistent between samples (150 to $300 \mathrm{ng} / \mu \mathrm{l})$. DNA and RNA concentrations were measured using a spectrophotometer (NanoDrop Technologies, Wilmington, DE). Prior to qPCR analyses, $11.55 \mu$ l of RNA was retro-transcribed using the reverse txtA primer (St-Onge et al. 2011) and the TaqMan Reverse Transcription Reagents Kit (Applied Biosystems, Carlsbad, CA) for a total reaction volume of $30 \mu l$.

qPCR pathogenic Streptomyces spp. population determination and RT-qPCR analysis of txtA gene expression. The primers and TaqMan probe targeting $t x t A$ have previously been described (St-Onge et al. 2011) and were purchased from Integrated DNA Technologies (Coralville, IA) and Applied Biosystems, respectively. Reactions $(20 \mu \mathrm{l})$ were prepared using the iTaq reagent $(10 \mu \mathrm{l}$ of iTaq Supermix [Bio-Rad, Mississauga, Canada)], primers and probe [200 $\mathrm{nM}$ ], and $4.8 \mu \mathrm{l}$ of cDNA or 1:10 diluted DNA). qPCRs were performed in triplicate and included no-template controls using a BioRad CFX Connect (Bio-Rad). Each PCR plate included a standard curve, determined by serial dilutions of a known number of plasmids containing $t x t A$, in order to obtain absolute gene copy numbers. Plasmid standards were developed as previously described (DeCoste et al. 2010).

Extraction of plant RNA and RT-qPCR gene expression analysis. Leaves were processed as previously described (Arseneault et al. 2014), extracting and purifying RNA from the homogenized leaf samples, and diluting the RNA to $30 \mathrm{ng} / \mu \mathrm{l}$ prior to reverse transcription (RT). RNA quality and concentration was assessed using an Experion system (Bio-Rad). Synthesis of cDNA was accomplished using oligo-dT and the TaqMan Reverse Transcription Reagents Kit (Applied Biosystems). The resulting cDNA was diluted 1:2. The expression of eight genes was targeted (ChtA, PR-1b, PR-2, PR-5, $E R F 3, L O X, P A L-2$, and $P I N 2)$ and results were normalized using two reference genes (EF1- $a$ and $C y P$ ). RT-qPCR analysis was accomplished as previously described, using primers and probes already developed (Arseneault et al. 2014).

Statistical analyses. Two factor (time and treatment) or one factor (treatment) analyses of variance were performed with subsequent Tukey-Kramer adjustments to determine significant differences between treatments $(P<0.05)$. Mixed models were used to include a random factor, which removes variation due to the replication of the experiment in both years. For the control and single LBUM223 application treatments, results did not differ significantly between 2012 and 2013. Subsequently, the data for these treatments were combined and variation was accounted for using the mixed model analysis. The interaction between factors was verified. Population and gene expression data ( $t x t A$ and defense-related plant genes) required log transformations to achieve suitable homogeneity and normality, while tuber weight and common scab severity and incidence data required no transformation. Each harvested plant and its associated soil sample and tubers, at a given time, represents an independent experimental unit, and multiple data originating from this unit were averaged prior to analysis (such as scab coverage). Measures obtained from technical replicates originating from the same sample were averaged prior to statistical analysis (including qPCR triplicates). As the number of plants harvested per plot at the end of the season was different than harvests at 3, 5, 7, 9, and 11 weeks, this time point was analyzed separately with regards to scab coverage, incidence and tuber weight. The SAS Statistical Analysis Software version 9.3 (SAS Institute, Cary, NC) was used for all analyses. 


\section{RESULTS}

Plant growth and common scab symptoms. The harvest of one plant per plot occurred at 3, 5, 7, 9, and 11 weeks. At week 7, most plants had flowered and started producing tubers (weighing on average $7 \mathrm{~g}$, data not shown), enabling the collection of geocaulosphere soil. Only few scab lesions were observed until week 11, when tubers were more sizeable (weighing on average $65 \mathrm{~g}$, data not shown). There were no significant differences in the percentage of scab coverage or incidence between all treatments for weeks 7, 9, and 11. However, data analysis revealed an increase in scab incidence and severity of symptoms over time for all treatments combined (Table 1$)$. Scab incidence $(P=0.0081)$ and coverage $(P=0.0096)$ were significantly higher at week 11 than any previous harvesting date.

Biological control of common scab. Common scab symptoms were also assessed on tubers harvested at the end of the 4-month growing season and analyzed separately from all other time points as more plants were harvested (Fig. 1). The average coverage of common scab per tuber was significantly reduced by approximately $30 \%$ in plots having received biweekly applications with LBUM223 compared with control $(P=0.041)$ and

TABLE 1. Development of common scab symptoms in time for all treatments combined

\begin{tabular}{lcc}
\hline $\begin{array}{l}\text { Weeks after } \\
\text { planting }\end{array}$ & $\begin{array}{c}\text { Incidence* } \\
(\%) \pm \text { SEM }^{\mathrm{y}}\end{array}$ & $\begin{array}{c}\text { Scab coverage } \\
(\%) \pm \text { SEM }^{\mathrm{z}}\end{array}$ \\
\hline 7 & $26.04 \pm 6.83 \mathrm{a}$ & $3.15 \pm 0.50 \mathrm{c}$ \\
9 & $23.58 \pm 8.18 \mathrm{a}$ & $2.62 \pm 0.66 \mathrm{c}$ \\
11 & $48.45 \pm 13.29 \mathrm{~b}$ & $5.27 \pm 1.37 \mathrm{~d}$ \\
\hline
\end{tabular}

$\mathrm{y}$ Incidence refers to the proportion of tubers having more than $5 \%$ scab coverage. SEM, standard error of the mean. Letters a and $\mathrm{b}$ indicate statistically significant differences $(P=0.0081)$.

${ }^{\mathrm{z}}$ Letters $\mathrm{c}$ and $\mathrm{d}$ indicate statistically significant differences $(P=0.0096)$.

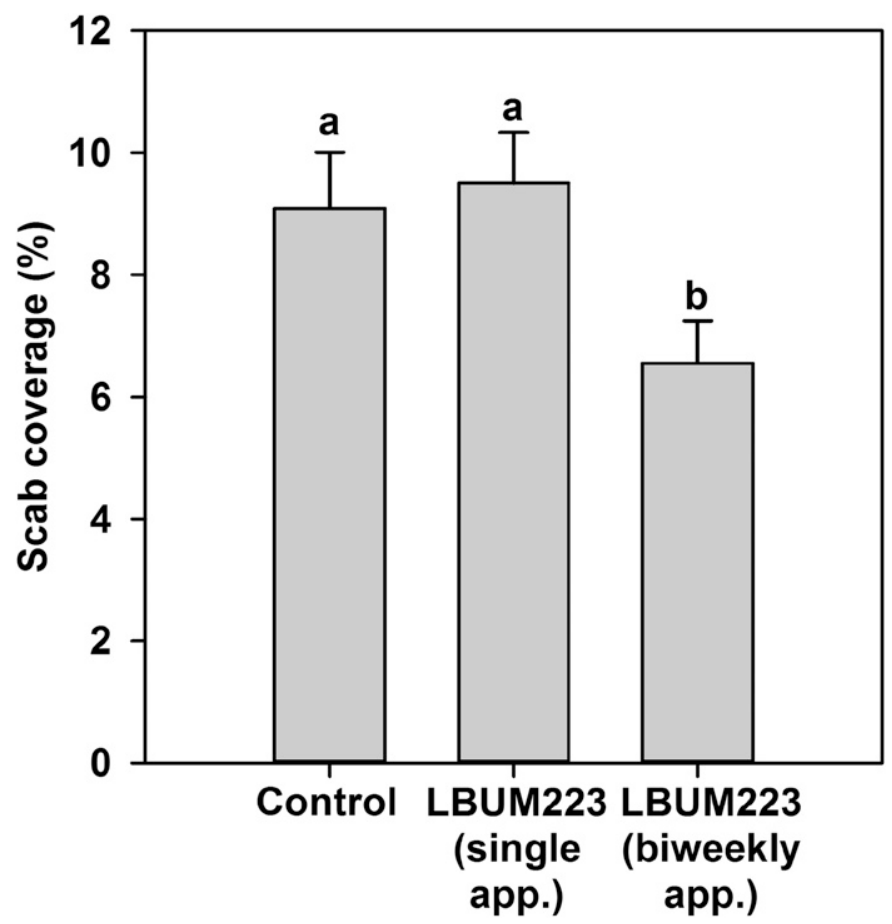

Fig. 1. Tuber scab coverage at harvest (week 17). Percentage of scab coverage was averaged for all tubers belonging to the same plant. Values are presented as mean \pm standard error of the mean. Significant differences between treatments are presented $(P<0.05)$ using the letters a and b. Pseudomonas fluorescens LBUM223 was applied either once at planting (single app.) or at biweekly intervals (biweekly app.). single application $(P=0.014)$ treatments. Visually, scab lesions were generally more superficial and isolated. Treatments had no significant effect on the incidence of common scab on tubers.

Increase in potato tuber yield. Tuber weight was assessed for each plot at the end of the growing season (Fig. 2). Biweekly applications of LBUM223 significantly increased potato tuber yield by $46 \%(P=0.048)$ compared with control plots. Results for the treatment with a single application with LBUM223 were more variable, even within the same experimental year, and therefore did not significantly differ from the control plots or the ones having received biweekly inoculations with LBUM223.

Soil population dynamics of pathogenic Streptomyces spp. and $\boldsymbol{t x t A}$ gene expression. The abundance of pathogenic Streptomyces spp. in the geocaulosphere soil was quantified at weeks 7, 9, and 11. Absolute quantification of txtA by qPCR from DNA extracted from geocaulosphere soil samples permitted the quantification of pathogenic Streptomyces spp. cell numbers. There were no differences in populations between the different treatments, at any sampling date (Fig. 3). Pathogenic Streptomyces populations also did not vary over time, with approximately $4 \times 10^{7}$ bacteria/g of soil, when averaged over all treatments and time. Gene expression values for $t x t A$ (Fig. 4) were obtained by dividing total $t x t A$ RNA transcript copy numbers by $t x t A$ gene copy numbers; thus, the results are expressed in terms of number of txtA transcripts/pathogenic Streptomyces spp. cell. Statistical analyses revealed an interaction between time and treatment factors. Multiple comparisons revealed that at week 11 only, there was a significant reduction in $t x t A$ gene expression in the geocaulosphere associated with biweekly applications of LBUM223 when compared with control plots $(P=0.0212)$.

Defense-related gene expression in potato leaves. The expression of four SA-associated genes (ChtA, $P R-1 b, P R-2$, and $P R-5)$ (Fig. 5) and four ET/JA-associated genes (ERF3, LOX, PAL-2, and PIN2) (Fig. 6) was quantified in the leaves of potato plants harvested at $3,5,7,9$, and 11 weeks. For all targeted genes, the expression did not vary between treatments or in time.

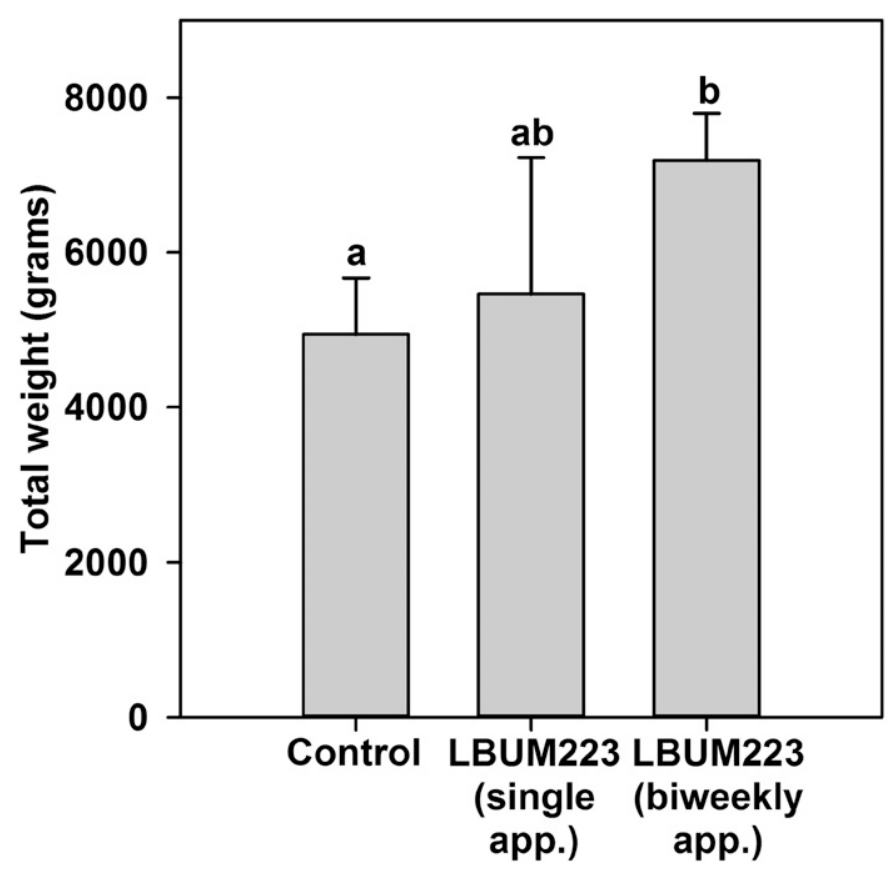

Fig. 2. Total weight of tubers at harvest (week 17). Values are presented as mean \pm standard error of the mean. Significant differences between treatments are presented $(P=0.048)$ using the letters a and b. Pseudomonas fluorescens LBUM223 was inoculated either once at planting (single app.) or at biweekly intervals (biweekly app.). 


\section{DISCUSSION}

This study sought to evaluate the biological control capability of P. fluorescens LBUM223 against common scab of potato under natural field conditions, and to characterize the in situ biocontrol mechanisms involved. Such a validation is essential as successful BCAs in controlled experiments can be inconsistent under field conditions. Results showed a significant though modest reduction in common scab symptoms in tubers harvested at the end of the 4-month growing season when LBUM223 was applied biweekly. Repeated applications with LBUM223 appear essential for reducing the disease, as a single application at planting was not successful in reducing common scab symptoms. Other studies have also demonstrated successful reduction in disease symptoms when using multiple applications of biological control treatments (Gachango et al. 2012; Gent and Schwartz 2005; Kirk et al. 2013) and some commercially available biocontrol products also recommend multiple applications on their labels (Serenade Optimum, Bayer CropScience LP, Research Triangle Park, NC, every 7 to 10 days), (BlightBan A506, Nufarm, Burr Ridge, IL, three to four applications), (BioJect Spot-Less, Eco Soil Systems Inc., San Diego, CA, daily). LBUM223 was previously shown to significantly reduce common scab symptoms caused by $S$. scabies under controlled conditions using a single application with LBUM223 at planting, using the same concentration as the one used in this study (Arseneault et al. 2013). However, the sterilized field soil used to adequately establish $S$. scabies populations under controlled conditions (Arseneault et al. 2013) probably led to a reduction in competition with other microorganisms. This suggests that the establishment of LBUM223 under complex field conditions is more challenging, potentially due to biotic factors such as competition with the endogenous microflora, as well as abiotic factors such as weather and soil physiochemical conditions. A difficulty in maintaining soil populations has also been observed for several strains of Pseudomonas inoculated in the field (Viebahn

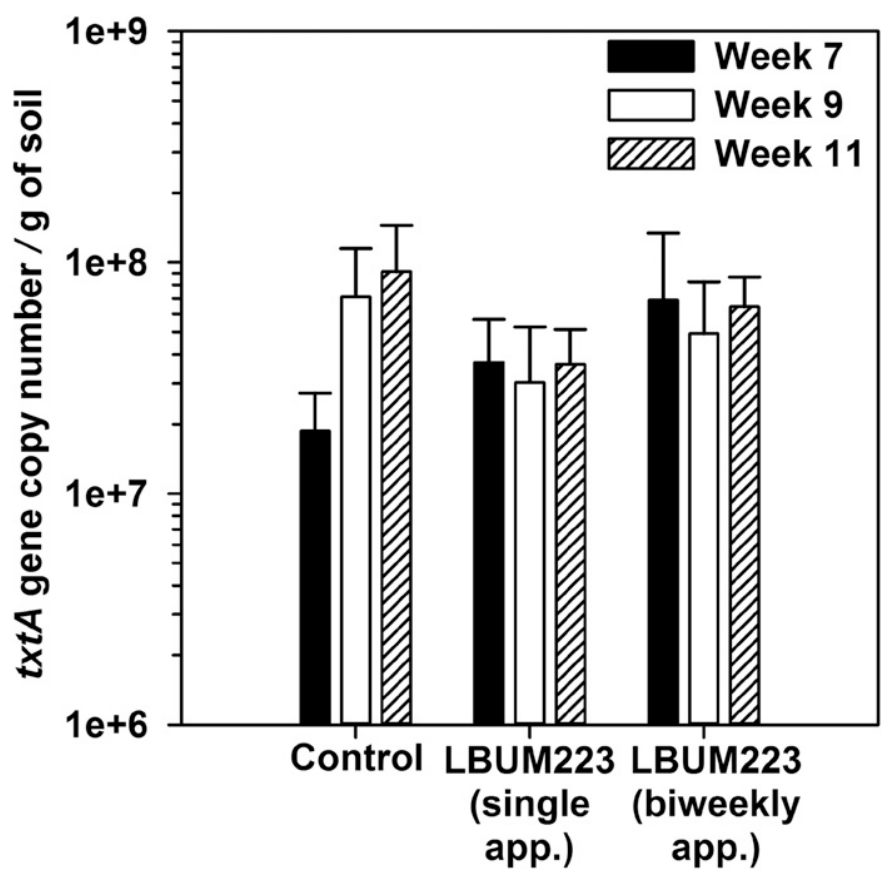

Fig. 3. Soil populations of pathogenic Streptomyces spp. in the geocaulosphere, shown as the number of txtA gene copy numbers per gram of geocaulosphere soil. Values are presented as mean \pm standard error of the mean. No interaction was obtained between time and treatment factors. There were no significant differences observed. Pseudomonas fluorescens LBUM223 was inoculated either once at planting (single app.) or at biweekly intervals (biweekly app.). et al. 2003). Further studies analyzing soil populations of LBUM223 and understanding how biotic and abiotic factors affect its biocontrol ability will be essential in furthering the development of LBUM223 as a commercial BCA. Previous field studies using another PCA-producing $P$. fluorescens have shown that its biocontrol efficiency highly depended on several soil properties, including ammonium, iron and zinc content, as well as soil $\mathrm{pH}$, percentage of silt and calcium-exchange capacity (Ownley et al. 2003). Biocontrol ability of LBUM223 will also need to be validated in other fields where disease pressure is more severe, as the field used displayed low common scab disease pressure, and therefore only a modest, although significant reduction in symptoms was observed.

There are other reports of biological control of common scab under field conditions, using mainly nonpathogenic Streptomyces species (Beauséjour et al. 2003; Hiltunen et al. 2009; Wanner et al. 2014). These species, being of the same genus as the pathogen, are able to control disease via competition (Hiltunen et al. 2009), but have the disadvantage of being able to potentially acquire the pathogenicity island responsible for causing common scab through horizontal gene transfer (Loria et al. 2006). Interestingly, another Pseudomonas (P. mosselii) was also shown able to control common scab as well as promote tuber growth in the field (Singhai et al. 2011); however, no clear mechanisms were provided.

Biweekly applications with LBUM223 significantly increased tuber yield by approximately $46 \%$ compared with control. These results complement the ones obtained in a previous study, which showed that LBUM223 was capable of increasing potato plant weight (tuber weight was not evaluated) under controlled conditions (Arseneault et al. 2013). Other studies have also reported that growth-promoting Pseudomonas spp. were able to increase potato yield (Bakker et al. 2007; Kloepper et al. 1980). Although a single application of LBUM223 did not significantly increase

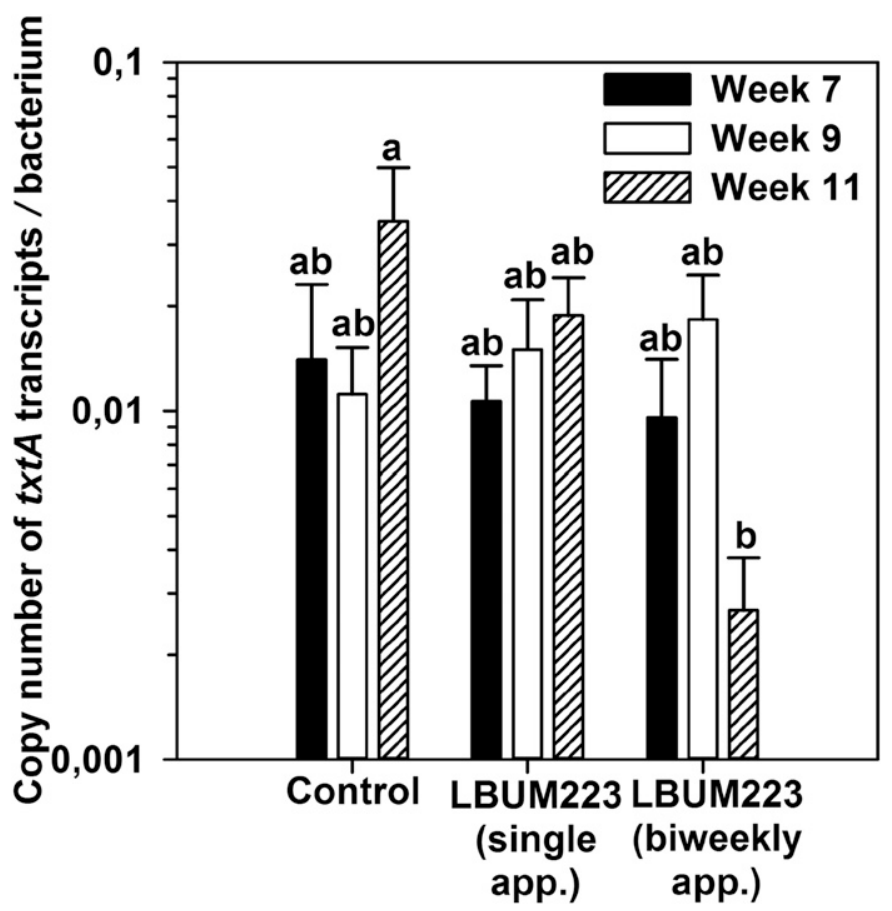

Fig. 4. $t x t A$ gene expression in the geocaulosphere, shown as the total number of $t x t A$ transcripts divided by the total cell number ( $t x t A$ gene copy number) per gram of geocaulosphere soil. Values are presented as mean \pm standard error of the mean. An interaction was obtained between time and treatment factors, resulting in the comparison of all combinations of treatment and time values to each other. Significant differences between treatments are presented $(P=$ 0.0212 ) using the letters a and b. Pseudomonas fluorescens LBUM223 was inoculated either once at planting (single app.) or at biweekly intervals (biweekly app.). 
tuber yield compared with the control, the results obtained also did not significantly differ from the biweekly applications treatment, suggesting an intermediate effect. This is potentially linked to the limited establishment capability of LBUM223 when applied only once, but remains to be verified.

Three main mechanisms potentially involved in LBUM223mediated biological control of common scab under field conditions were studied: (i) reduction in pathogen populations, (ii) alteration of the transcriptional activity of $t x t A$, a key pathogenesis gene in scabcausing Streptomyces spp., and (iii) induction of systemic plant defense responses. The expression profile of eight systemic defense-related genes in potato leaves at weeks $3,5,7,9$, and 11 showed no apparent implication of induced systemic resistance in the reduction of scab symptoms, as no significant differences were found between treatments. This supports previous findings, using potted potato plants in a controlled environment, which showed that although LBUM223 was able to induce the overexpression of two defense-related genes in potato, $L O X$ and $P R-5$, this did not significantly contribute to disease control (Arseneault et al. 2014). The lack of change in expression could be due to several factors. Plants in a natural setting, such as a field, are subject to meteorological changes, inducing stress caused by extremes in temperature and soil water content. They are also exposed to a high diversity of organisms such as bacteria, fungi, insects, etc. Factors such as these have brought on questions as to whether plants in the field are already maximally induced for a defense response (Walters 2009; Walters et al. 2013), regardless of whether or not an ISRinducer is applied.

We also examined if biological control was achieved through reduced scab-causing bacterial populations. No significant change in the geocaulosphere populations of pathogenic Streptomyces spp. was found between treatments. Additionally, pathogen populations, as well as the resulting disease pressure, were consistent in both trial years. We previously reported that the antibiotic PCA, produced by LBUM223, could inhibit the growth of S. scabies in vitro (St-Onge et al. 2011), and although PCA
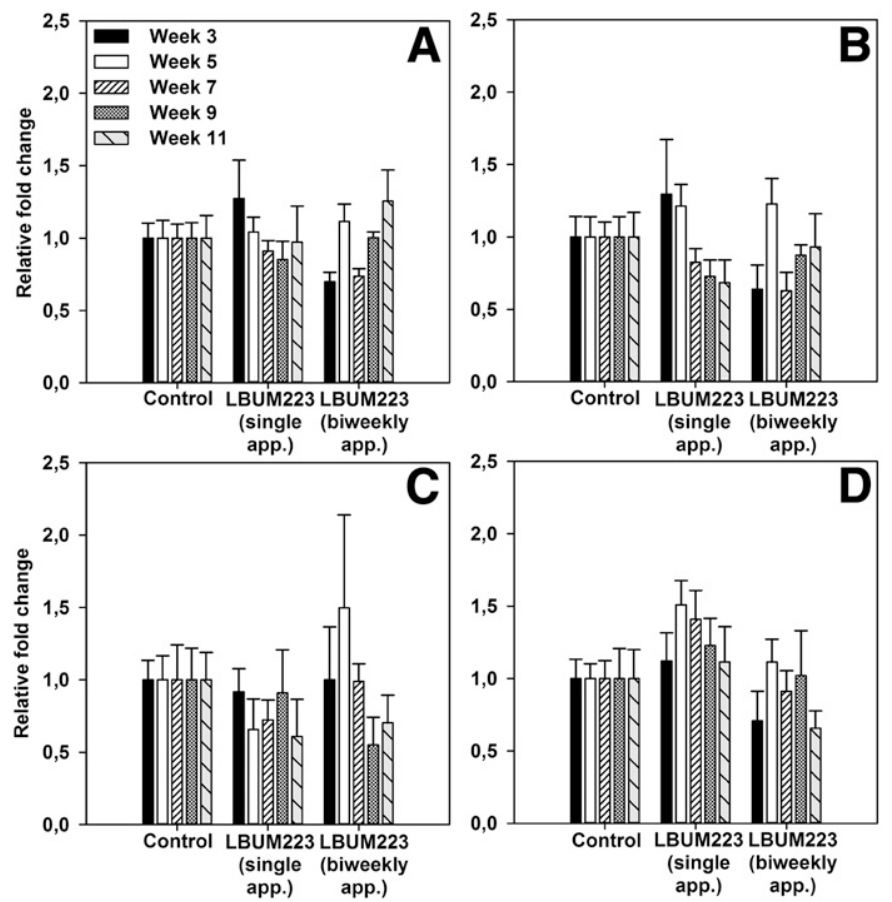

Fig. 5. Expression of salicylic acid-related genes A, ChtA, B, $P R-1 b, \mathbf{C}, P R-2$, and D, $P R-5$ in potato leaves at $3,5,7,9$, and 11 weeks. Values are presented as mean \pm standard error of the mean. There were no significant differences between treatments. Pseudomonas fluorescens LBUM223 was inoculated either once at planting (single app.) or at biweekly intervals (biweekly app.). production was also essential in controlling common scab disease development under controlled conditions, LBUM223 did not reduce geocaulosphere $S$. scabies populations (Arseneault et al. 2013), supporting current field results. This suggests that under both controlled and field conditions, PCA-associated toxicity did not play a significant role in disease reduction, and suggests another role for PCA in this system.

The most likely mechanism of action utilized by LBUM223 in the biocontrol of common scab is the modulation in the metabolism of pathogenic Streptomyces spp., leading to reduced virulence. The expression of $t x t A$, a key gene involved in the biosynthesis of the thaxtomin A toxin by pathogenic Streptomyces spp., was quantified. At week 11, the expression of txtA by pathogenic Streptomyces spp. in the geocaulosphere was significantly repressed in samples receiving biweekly applications of LBUM223 compared with the control, whereas a single inoculation with LBUM223 did not differ significantly from either the control or the biweekly applications, suggesting an intermediate effect on $t x t A$ gene expression. An explanation as to why the reduction in $t x t A$ expression only occurs 11 weeks after planting could be that prior to this time point, lesions caused by the spreading pathogenic Streptomyces spp. were limited, as the severity of symptoms increased significantly at week 11 . While initial infection by scab-causing Streptomyces spp. is thought to occur between 3 and 20 days after tuber initiation, when tubers are most susceptible (Khatri et al. 2009), the growth and expansion of the potato and further colonization of its tissues result in visible lesions only later in the growing season. As thaxtomin A biosynthesis genes are induced by the binding of the cellulose degradation products, cellobiose (Loria et al. 2008) or cellotriose (Johnson et al. 2007), in the presence of plant suberin (Lerat et al. 2010), the increase in potato scab lesion coverage at week 11 may have resulted in a greater expression of txtA by the pathogenic Streptomyces spp. It is also possible that prior to the week 11 time point, LBUM223 populations were not yet fully established, or that production of PCA, which was essential to the down-regulation of txtA expression under controlled conditions (Arseneault et al.
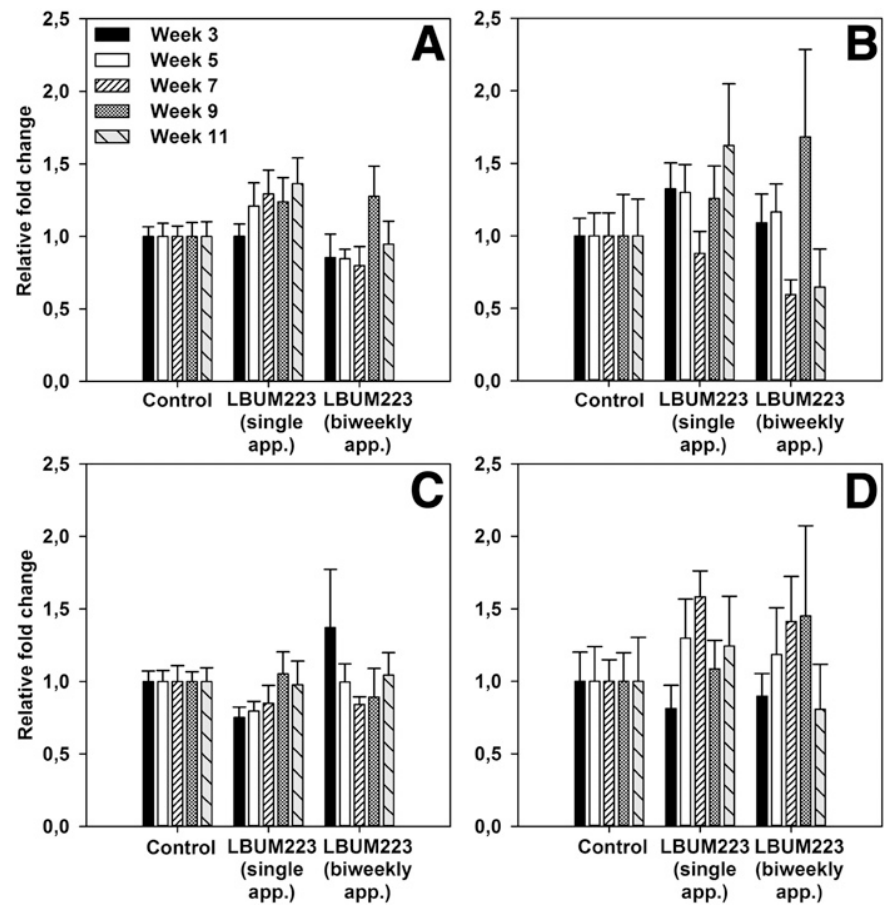

Fig. 6. Expression of ethylene/jasmonic acid-related genes A, ERF3, B, LOX, C, $P A L-2$, and D, PIN2 in potato leaves at 3, 5, 7, 9, and 11 weeks. Values are presented as mean \pm standard error of the mean. There were no significant differences between treatments. Pseudomonas fluorescens LBUM223 was inoculated either once at planting (single app.) or at biweekly intervals (biweekly app.). 
2013), was too low to have an effect. This remains to be validated by verifying the dynamics of LBUM223 populations and its production of PCA. This reduction in $t x t A$ gene expression likely led to a decrease in thaxtomin A production, since it has been previously shown that thaxtomin A accumulation closely follows txtA gene expression (St-Onge et al. 2008).

These results on $t x t A$ gene expression correlate with the reduction in common scab symptoms observed when LBUM223 was applied biweekly and also support previous studies where the downregulation of $t x t A$ gene expression by LBUM223 was reported under in vitro (St-Onge et al. 2011) and controlled growth chamber conditions (Arseneault et al. 2013). Taken together, these results strongly suggest that a down-regulation in $t x t A$ gene expression in pathogenic Streptomyces spp. is one of the main mechanism utilized by LBUM223 to control common scab development. Phenazines are active redox chemicals that are able to interfere with cellular electron transport chains, potentially generating toxic reactive oxygen species, but having also been shown capable of generally binding DNA and interfering with transcription (Mavrodi et al. 2006). The effect of PCA on pathogenic Streptomyces is currently unknown and remains to be elucidated, but as it affects a broad spectrum of cellular activities, it is likely that the expression of other genes involved to pathogenicity or virulence may be altered. Further transcriptomics studies of global changes in S. scabies expression profile when exposed to LBUM223 will provide further answers on other possible genetic targets of PCA. To our knowledge, this is the first demonstration that a Pseudomonas strain can directly alter the transcriptional activity of a key pathogenesis gene in a plant pathogen under field conditions, contributing to disease control. The discovery of $P$. fluorescens LBUM223's capability in increasing potato yield and its potential in controlling common scab disease development under field conditions is promising for the future commercialization of LBUM223 as a microbial inoculant displaying both biofertilizing and biocontrol capabilities. Additional studies will however be needed to optimize the timing of LBUM223 applications, as well as make these applications compatible with standard potato agricultural practices to achieve the desired outcomes.

\section{ACKNOWLEDGMENTS}

The authors would like to thank C. Lanteigne, A. Novinscak, C. Morrison (Université de Moncton, Moncton, NB, Canada), and S. Whitney (Agriculture and Agri-Food Canada, Fredericton, NB, Canada) for their much appreciated technical assistance, as well as G. Moreau (Université de Moncton) for sharing suggestions regarding statistical analyses. This study was supported by Natural Sciences and Engineering Research Council (NSERC) and New Brunswick Innovation Foundation (NBIF) grants to M. Filion. A doctoral Alexander Graham Bell Canada Graduate Scholarship (NSERC) was awarded to T. Arseneault.

\section{LITERATURE CITED}

Arseneault, T., Goyer, C., and Filion, M. 2013. Phenazine production by Pseudomonas sp. LBUM223 contributes to the biological control of potato common scab. Phytopathology 103:995-1000.

Arseneault, T., Pieterse, C. M. J., Gérin-Ouellet, M., Goyer, C., and Filion, M. 2014. Long-term induction of defense gene expression in potato by Pseudomonas sp. LBUM223 and Streptomyces scabies. Phytopathology 104:926-932.

Bakker, P. A. H. M., Pieterse, C. M. J., and van Loon, L. C. 2007. Induced systemic resistance by fluorescent Pseudomonas spp. Phytopathology 97:239-243.

Beauséjour, J., Clermont, N., and Beaulieu, C. 2003. Effect of Streptomyces melanosporofaciens strain EF-76 and of chitosan on common scab of potato. Plant Soil 256:463-468.

Bürgmann, H., Widmer, F., Sigler, W. V., and Zeyer, J. 2003. mRNA extraction and reverse transcription-PCR protocol for detection of nifH gene expression by Azotobacter vinelandii in soil. Appl. Environ. Microbiol. 69: 1928-1935.

Chin-A-Woeng, T. F. C., Bloemberg, G. V., and Lugtenberg, B. J. J. 2003. Phenazines and their role in biocontrol by Pseudomonas bacteria. New Phytol. 157:503-523.
DeCoste, N. J., Gadkar, V. J., and Filion, M. 2010. Verticillium dahliae alters Pseudomonas spp. populations and HCN gene expression in the rhizosphere of strawberry. Can. J. Microbiol. 56:906-915.

Dees, M. W., and Wanner, L. A. 2012. In search of better management of potato common scab. Potato Res. 55:249-268.

Gachango, E., Kirk, W. W., and Schafer, R. 2012. Effects of in-season cropprotection combined with postharvest applied fungicide on suppression of potato storage diseases caused by oomycete pathogens. Crop Prot. 41:42-48.

Gent, D., and Schwartz, H. 2005. Management of Xanthomonas leaf blight of onion with a plant activator, biological control agents, and copper bactericides. Plant Dis. 89:631-639.

Goyer, C., Vachon, J., and Beaulieu, C. 1998. Pathogenicity of Streptomyces scabies mutants altered in thaxtomin A production. Phytopathology 88:442-445.

Healy, F. G., Krasnoff, S. B., Wach, M., Gibson, D. M., and Loria, R. 2002. Involvement of a cytochrome P450 monooxygenase in thaxtomin A biosynthesis by Streptomyces acidiscabies. J. Bacteriol. 184:2019-2029.

Hiltunen, L. H., Ojanperä, T., Kortemaa, H., Richter, E., Lehtonen, M. J., and Valkonen, J. P. T. 2009. Interactions and biocontrol of pathogenic Streptomyces strains co-occurring in potato scab lesions. J. Appl. Microbiol. 106: $199-212$

Johnson, E. G., Joshi, M. V., Gibson, D. M., and Loria, R. 2007. Cellooligosaccharides released from host plants induce pathogenicity in scabcausing Streptomyces species. Physiol. Mol. Plant Pathol. 71:18-25.

Khatri, B. B., Tegg, R. S., Brown, P. H., and Wilson, C. R. 2009. Infection of potato tubers with the common scab pathogen Streptomyces scabiei in a soil-less system. J. Phytopathol. 158:453-455.

Khatri, B. B., Tegg, R. S., Brown, P. H., and Wilson, C. R. 2011. Temporal association of potato tuber development with susceptibility to common scab and Streptomyces scabiei-induced responses in the potato periderm. Plant Pathol. 60:776-786.

Kinkel, L. L., Bowers, J. H., Shimizu, K., Neeno-Eckwall, E. C., and Schottel, J. L. 1998. Quantitative relationships among thaxtomin A production, potato scab severity, and fatty acid composition in Streptomyces. Can. J. Microbiol. 44:768-776.

Kirk, W. W., Gachango, E., Schafer, R., and Wharton, P. S. 2013. Effects of in-season crop-protection combined with postharvest applied fungicide on suppression of potato storage diseases caused by Fusarium pathogens. Crop Prot. 51:77-84.

Kloepper, J. W., Schroth, M. N., and Miller, T. D. 1980. Effects of rhizosphere colonization by plant growth-promoting rhizobacteria on potato plant development and yield. Phytopathology 70:1078-1082.

Lambert, D. H., and Loria, R. 1989. Streptomyces scabies sp. nov., nom. rev. Int. J. Syst. Bacteriol. 39:387-392.

Lawrence, C. H., Clark, M. C., and King, R. R. 1990. Induction of common scab symptoms in aseptically cultured potato tubers by the vivotoxin, thaxtomin. Phytopathology 80:606-608.

Lerat, S., Simao-Beaunoir, A.-M., Wu, R., Beaudoin, N., and Beaulieu, C. 2010. Involvement of the plant polymer suberin and the disaccharide cellobiose in triggering thaxtomin A biosynthesis, a phytotoxin produced by the pathogenic agent Streptomyces scabies. Phytopathology 100:91-96.

Loper, J. E., Hassan, K. A., Mavrodi, D. V., Davis, E. W., and Lim, C. K. 2012. Comparative genomics of plant-associated Pseudomonas spp.: Insights into diversity and inheritance of traits involved in multitrophic interactions. PLoS Genet. 8:e1002784.

Loria, R., Bignell, D. R. D., Moll, S., Huguet-Tapia, J. C., Joshi, M. V., Johnson, E. G., Seipke, R. F., and Gibson, D. M. 2008. Thaxtomin biosynthesis: The path to plant pathogenicity in the genus Streptomyces. Antonie van Leeuwenhoek 94:3-10.

Loria, R., Kers, J., and Joshi, M. 2006. Evolution of plant pathogenicity in Streptomyces. Annu. Rev. Phytopathol. 44:469-487.

Mavrodi, D. V., Blankenfeldt, W., and Thomashow, L. S. 2006. Phenazine compounds in fluorescent Pseudomonas spp. biosynthesis and regulation. Annu. Rev. Phytopathol. 44:417-445.

Ownley, B. H., Duffy, B. K., and Weller, D. M. 2003. Identification and manipulation of soil properties to improve the biological control performance of phenazine-producing Pseudomonas fluorescens. Appl. Environ. Microbiol. 69:3333-3343.

Paulin, M. M., Novinscak, A., St-Arnaud, M., Goyer, C., DeCoste, N. J., Privé, J.-P., Owen, J., and Filion, M. 2009. Transcriptional activity of antifungal metabolite-encoding genes phlD and hcnBC in Pseudomonas spp. using qRT-PCR. FEMS Microbiol. Ecol. 68:212-222.

Pieterse, C. M. J., Van der Does, D., Zamioudis, C., Leon-Reyes, A., and Van Wees, S. C. M. 2012. Hormonal modulation of plant immunity. Annu. Rev. Cell Dev. Biol. 28:489-521.

Pieterse, C. M. J., Zamioudis, C., Berendsen, R. L., Weller, D. M., Van Wees, S. C. M., and Bakker, P. A. H. M. 2014. Induced systemic resistance by beneficial microbes. Annu. Rev. Phytopathol. 52:347-375.

Roquigny, R., Arseneault, T., Gadkar, V. J., Novinscak, A., Joly, D. L., and Filion, M. 2015. Complete genome sequence of the biocontrol 
strain Pseudomonas fluorescens LBUM223. Genome Announc. 3: e00443-15.

Singhai, P. K., Sarma, B. K., and Srivastava, J. S. 2011. Biological management of common scab of potato through Pseudomonas species and vermicompost. Biol. Control 57:150-157.

St-Onge, R., Gadkar, V. J., Arseneault, T., Goyer, C., and Filion, M. 2011. The ability of Pseudomonas sp. LBUM223 to produce phenazine-1carboxylic acid affects the growth of Streptomyces scabies, the expression of thaxtomin biosynthesis genes and the biological control potential against common scab of potato. FEMS Microbiol. Ecol. 75: 173-183.

St-Onge, R., Goyer, C., Coffin, R., and Filion, M. 2008. Genetic diversity of Streptomyces spp. causing common scab of potato in eastern Canada. Syst. Appl. Microbiol. 31:474-484.
Viebahn, M., Glandorf, D. C. M., Ouwens, T. W. M., Smit, E., Leeflang, P., Wernars, K., Tomashow, L. S., van Loon, L. C., and Bakker, P. A. H. M. 2003. Repeated introduction of genetically modified Pseudomonas putida WCS358r without intensified effects on the indigenous microflora of field-grown wheat. Appl. Environ. Microbiol. 69:3110-3118.

Walters, D. R. 2009. Are plants in the field already induced? Implications for practical disease control. Crop Prot. 28:459-465.

Walters, D. R., Ratstep, J., and Havis, N. D. 2013. Controlling crop diseases using induced resistance: Challenges for the future. J. Exp. Bot. 64:1263-1280.

Wanner, L. A., Kirk, W. W., and Qu, X. S. 2014. Field efficacy of nonpathogenic Streptomyces species against potato common scab. J. Appl. Microbiol. 116:123-133.

Weller, D. M. 2007. Pseudomonas biocontrol agents of soilborne pathogens: Looking back over 30 years. Phytopathology 97:250-256. 